\title{
As Barreiras da Criatividade dos Egressos do Ensino Superior EAD e Presencial
}

The Barriers of Creativity for Higher Education Graduates Distance Learning and Classroom

\author{
Joseli Konig Ramos ${ }^{1 *}$ \\ Jeane Caroline Boeira' \\ Maria José Carvalho de Souza \\ Domingues $^{1}$ \\ Adriana Kroenke ${ }^{1}$ \\ 1 Universidade Regional de Blumenau - \\ Furb. Rua Jacob Dreher, 64. Mato Preto \\ - São Bento do Sul, SC - Brasil \\ *jkramos@furb.br
}

\section{Resumo}

A criatividade está presente em nosso dia a dia. Ela se destaca tanto nos ambientes pessoais, assim como nos escolares e profissionais. Com este artigo, tem-se o objetivo de verificar se há barreiras na criatividade dos egressos do ensino superior nas modalidades de ensino EAD (Ensino a distância) e presencial, pluricurriculares. Para isso, foi aplicado um questionário por escala likert de 7 pontos para 283 egressos do ensino superior. Realizou-se o embasamento teórico sobre criatividade e o indivíduo, suas barreiras elencadas em quatro construtos, inibição/timidez; falta de tempo/oportunidade; repressão Social; falta de motivação. Os dados foram analisados através de correlação, obtendo, como resultado das análises dos dados, a indicação de que ambos os ensinos se correlacionam de forma positiva quanto às barreiras do desenvolvimento da criatividade para o Ensino Presencial e Ensino EAD. Há de se considerar que o Ensino EAD ainda se mostra com resultados superiores, sendo possível encontrar fundamentos adicionais e explicações mais detalhadas sobre o tema.

Palavras-chave: Criatividade. Ensino superior. Ensino a distância. Ensino presencial.

\section{(c) (1)}

Recebido 08/ 02/ 2020 Aceito 03/ 06/ 2020

Publicado 12/ 06/ 2020

\section{COMO CITAR ESTE ARTIGO}

ABNT: RAMOS, J. K. et al. As Barreiras da Criatividade dos Egressos do Ensino Superior EAD e Presencial. EaD em Foco, V10, e965. 2020. DOI: https://doi.org/10.18264/eadf.v10i1.965 


\title{
The Barriers of Creativity for Higher Education Graduates Distance Learning and Classroom
}

\begin{abstract}
Creativity is present in our daily lives. It excels in personal environments as well as in school and professional settings. This article aims to verify if there are barriers in the creativity of the graduates of higher education in the modalities of distance education and face-to-face modality, pluricurricular. For this, a 7-point likert scale questionnaire was applied to 283 graduates from higher education. The theoretical basis on creativity and the individual, their barriers listed in four constructs, inhibition / shyness; lack of time / opportunity; social repression; and lack of motivation. The data were analyzed through correlation, obtaining a result of the data analysis, the indication that both teachings correlate positively as the barriers to the development of creativity for classroom teaching and distance learning. It should be considered that distance learning still shows superior results, and it is possible to find additional foundations and more explanations that are detailed on the subject.
\end{abstract}

Keywords: Creativity. University education. E-learning. On-campus teaching.

\section{Introdução}

A criatividade está presente nos vários segmentos da vida humana; o que se espera é o estímulo às chamadas universidades criativas, em que a criatividade se manifesta no ensino, no aprendizado, na pesquisa, no conhecimento gerado, no ambiente, formando uma cultura que resulta, em última instância, na capacidade cognitiva dos estudantes de serem inovadores (BARBIERI, 2018). Pode-se verificar que as pesquisas realizadas com estudantes e professores universitários são em número reduzido, apesar da relevância dessa etapa da escolarização no sentido de propiciar condições para a conscientização e desenvolvimento das habilidades criativas durante a formação profissional, com vistas a preparar o aluno para fazer uso da sua criatividade (AMARAL; MARTINEZ, 2006).

Assim, ações criativas e habituais representam opções comportamentais concorrentes que podem ser influenciadas simultaneamente por múltiplos domínios da ação social (FORD, 1996). Também Gardner (2016) enfatiza as diferenças entre as formas de arte e vê a criatividade com diferentes características em cada arte, ciência e profissão específica. Um indivíduo trabalhando em contextos diversos, provavelmente, será exposto a ideias diferentes e incomuns; assim, se um indivíduo tiver contato com um grupo diverso de pessoas, a probabilidade de ele ter conhecimento ou de obter conhecimento de diferentes abordagens para um dado problema é aumentada (PERRY-SMITH; SHALLEY, 2003). Em um estudo, Morais e Almeida (2016) verificaram que mais de $80 \%$ dos alunos de ensino superior consideram como "importante" ou "muito importante" a criatividade para um bom desempenho acadêmico e para o trabalho profissional futuro, assim como cursos promocionais de competências criativas na universidade, quer para alunos, quer para docentes.

Nesse sentido, o objetivo do artigo é analisar se há relação entre a criatividade nos egressos do ensino superior diferenciando as modalidades de ensino EAD e Presencial e as suas barreiras, em cursos pluricurriculares. Para isso, foi utilizada a escala de Alencar (1999), que denominou sua escala como Inventário para Identificação de Barreiras à Criatividade Pessoal, em que analisou a criatividade pessoal sob os aspectos dos fatores de inibição/timidez, falta de tempo/oportunidade, repressão social e falta de motivação. 
Foi utilizada a correlação dos construtos, para medir as barreiras do ensino superior em relação à criatividade, comparando as modalidades EAD e presencial.

Após realizada a pesquisa e a geração dos dados, verificou-se, na correlação de Pearson, que houve associação positiva entre os fatores: inibição, oportunidade, repressão e motivação no Ensino EAD e no Ensino Presencial. Como contribuição, este artigo apresenta os resultados de correlação dos egressos do ensino superior em relação à criatividade dos cursos EAD e presencial, para toda a comunidade acadêmica e todos os indivíduos.

\subsection{Fundamentação Teórica}

Visto que a criatividade tem sido considerada como um elemento crítico para a sobrevivência de muitas corporações, a sua importância tem sido cada vez mais reconhecida por acadêmicos e profissionais de diversas áreas (DAVIS, 2004; ROBINSON, 2013). Diante de tantas publicações sobre criatividade, termos e definições, é necessário delimitar o que se entende por criatividade, seus limites, fronteiras e conceituações. Nesse sentido, fizemos uma compilação das diferentes definições de criatividade (Quadro 1).

Quadro 1: Definições de Criatividade

\begin{tabular}{|l|l|}
\hline $\begin{array}{l}\text { AMABILE et al. (1996); SHALLEY, } \\
\text { ZHOU e OLDHAM (2004) }\end{array}$ & $\begin{array}{l}\text { A criatividade é geralmente conceituada como a produção de } \\
\text { ideias novas e úteis. }\end{array}$ \\
\hline $\begin{array}{l}\text { O'REILLY e TUSHMAN (2004); } \\
\text { SHALLEY (2008) }\end{array}$ & $\begin{array}{l}\text { Às vezes, as ideias são rejeitadas prematuramente porque a ideia } \\
\text { era brilhante em conceito, mas falha na aplicação. No entanto, } \\
\text { com mais frequência, as ideias permanecem não implementadas } \\
\text { porque os indivíduos e as organizações concentram sua energia } \\
\text { na geração de ideias (por exemplo, eventos de brainstorming, cai- } \\
\text { xas de idéias, etc.), mas não investem atenção, esforços e recursos } \\
\text { na promoção e implementação do criativo, ideias que se originam } \\
\text { dessas iniciativas. }\end{array}$ \\
\hline BARON (1963) & $\begin{array}{l}\text { A pessoa criativa é, ao mesmo tempo, ingênua e experiente, } \\
\text { destrutiva e construtiva, ocasionalmente mais louca, mas inflexi- } \\
\text { velmente mais sã. “Mais positivamente: Sem conhecimento, sem } \\
\text { criação; sem estabilidade, sem flexibilidade; sem disciplina, sem } \\
\text { liberdade." }\end{array}$ \\
\hline TORRANCE (1988) & $\begin{array}{l}\text { Descreveu a criatividade como um processo que envolvia ver } \\
\text { problemas, formular hipóteses sobre soluções, avaliar as hipóte- } \\
\text { ses, revisá-las, se necessário, e comunicá-las a outras pessoas, não } \\
\text { apenas parecendo sugerir uma sequência de etapas, mas também } \\
\text { focalizar diretamente os processos envolvidos em cada etapa e } \\
\text { conceituá-los de maneira mais psicológica. }\end{array}$ \\
\hline
\end{tabular}

Fonte: Definições compiladas a partir de pesquisa bibliográfica.

Neste artigo, toma-se por base a teoria de criatividade de Kubie (1958), que complementa as contribuições da teoria psicanalítica apontando a flexibilidade como forma de liberdade para aprender pela experiência e para mudar, de acordo com as circunstâncias internas ou externas, respondendo aos estímulos. Kubie (1958) enfatiza o uso da livre associação como processo em que se dá o fenômeno da criatividade. Essas características individuais e ambientais são discutidas através do estudo da personalidade individual, intelectualidade, motivação intrínseca e extrínseca e outras influências do ambiente (KUBIE, 1958). 


\subsection{Criatividade e Indivíduo}

Muitos são os fatores que afetam a expressão da criatividade. Alguns desses fatores dizem respeito ao indivíduo; outros, ao ambiente de trabalho; ainda outros, à dimensão histórica e cultural da sociedade (ALENCAR; MARTINEZ, 1998).

Alencar (1997) entende que "se o indivíduo se percebe e se avalia como competente, capaz e criativo, ele tende a ter mais confiança em expressar ideias e em exibir comportamento criativo. Por outro lado, se o indivíduo se percebe como incapaz e não criativo, esta percepção irá refletir em suas ações, limitando as possibilidades de uma expressão mais plena de seu potencial e talento" (ALENCAR, 1997; SHALLEY, ZHOU e OLDHAM, 2004). O argumento de que as características pessoais e contextuais interagem entre si essencialmente afirma que certos contextos "combinam" com as características pessoais dos indivíduos e que essa correspondência resulta em altos níveis de criatividade dos funcionários (AMABILE, 1996).

Ford (1996) sugeriu que ações criativas e habituais são opções comportamentais concorrentes para um indivíduo. Os indivíduos podem ser criativos em seus empregos, gerando novas maneiras de realizar seu trabalho, elaborando novos procedimentos ou tendo ideias inovadoras e reconfigurando abordagens conhecidas em novas alternativas (PERRY-SMITH; SHALLEY, 2003). Dois trabalhos teóricos importantes sugeriram que o processo criativo envolve várias etapas, incluindo (1) identificar um problema / oportunidade; (2) reunir informações ou recursos; (3) gerar idéias; (4) avaliar, modificar e comunicar ideias (STEIN, 1967; AMABILE, 1996).

Pesquisas também destacam a capacidade de pensamento convergente como um determinante crítico da criatividade individual (CROPLEY \& CROPLEY, 2012; CROPLEY, 2006; RUNCO, 2004). Runco (2004) também argumentou que a criatividade requer uma combinação de pensamento divergente e convergente. Ele argumentou ainda que o pensamento convergente envolve "processos críticos" - e processo crítico significa não apenas que os processos são necessários para a criatividade, mas também que envolvem críticas aos resultados do pensamento divergente (RUNCO, 2004). Igualmente, pode-se dizer que a criatividade é baseada em motivação intrínseca (AMABILE, 1996): “O desejo de realizar uma atividade em prol da própria atividade, independentemente da recompensa externa". Assim, características contextuais têm efeitos consistentes e significativos sobre a criatividade dos indivíduos e a direção desses efeitos está alinhada com a perspectiva da motivação intrínseca (SHALLEY, ZHOU e OLDHAM, 2004). Para Talbot (1993), para que o indivíduo expresse a sua criatividade, é necessário que ele possua o motivo, os meios e a oportunidade.

\subsection{Barreiras da Criatividade}

Inúmeras são as barreiras que dificultam o indivíduo tirar proveito de seu potencial para criar. Algumas delas são de ordem eminentemente pessoal, e aqui poderíamos fazer referência às barreiras emocionais, perceptuais e intelectuais. Outras são de ordem social, estando diretamente ligadas a valores, normas e pressupostos cultivados na sociedade e que contribuem para manter adormecido o potencial para criar (ALENCAR, 1999). As barreiras da autoimagem reduzem a eficácia de um indivíduo no avanço das ideias de forma assertiva. Surgindo de uma falta de autoconfiança, a barreira contribui para a falta de confiança no valor das próprias ideias. $O$ indivíduo pode relutar em procurar ajuda e revelar sentimentos pessoais (RICKARDS, 1991). Para Perry e Smith (2003), uma vez que um alto nível de criatividade tenha sido alcançado, o indivíduo periférico se verá tornando-se relativamente mais central em posição, ficando mais exposto a pessoas e informações, estimulando novas ideias e insights criativos adicionais.

As barreiras analisadas se referem à inibição e timidez, onde entende-se como timidez "[...] a consciência da incapacidade, o medo do fracasso diante dos outros, o receio do juízo alheio, a preocupação de que vai errar ou de que, acertando, não será compreendido" (MOTTA FILHO, 1969). São estes fatores que 
afetam a pessoa considerada tímida; a preocupação com o que os "outros" podem achar ou falar pode acabar afetando sua vontade de criar.

Outro fator que se destaca como uma barreira se refere à falta de tempo ou oportunidade. Prigogine (2009), em seu artigo sobre Criatividade da natureza, Criatividade humana, coloca que "O homem não é o pai do tempo nem da evolução", e que, hoje em dia, a criatividade está ligada à irreversibilidade, à quebra de simetria temporal, por meio da qual o futuro e o passado desempenham papéis diferentes e que por muito tempo, a criatividade foi compreendida unicamente como dissipação, mas hoje faz parte da origem da criatividade da vida. E a vida só é possível quando ela se volta para o futuro, e o futuro é inovação (PRIGOGINE, 2009).

Consideramos ainda o fator repressão social, onde se nota a valorização de estudantes obedientes, conformistas e sociáveis, em detrimento daqueles que são questionadores, independentes e intuitivos, de maneira a apontar que comportamentos que caracterizam o indivíduo criativo não são valorizados na sala de aula, sendo, na maior parte das vezes, indesejados ou punidos (WECHSLER, 1998).

E, como último fator, a falta de motivação, na qual a contribuição advinda do conhecimento do processo criativo deriva do fato de tal processo estar associado a um sentimento de plenitude e de prazer, seja na atividade de produção de ideias, seja na sua colocação em prática (VERGARA, 1998). Alencar e Fleith (1993) observam que o instante de inspiração, em que surge a solução para o problema, costuma ser um momento de intensa alegria por parte do criador. O exercício do potencial criativo - que pode ocorrer em qualquer domínio de atividade - constitui, então, experiência intrinsecamente motivadora (VERGARA, 1998).

\subsection{Criatividade no Ensino Superior}

Importante considerar a instituição educativa como um dos espaços fundamentais para o desenvolvimento da criatividade dos alunos (AMARAL; MARTINEZ, 2006). Alencar e Fleith (2003), também ressaltam que as habilidades criativas são de crucial importância no processo de preparação dos alunos, para lidar com um mundo complexo e cheio de desafios. Castanho (2000) nos diz que as escolas precisam mudar. Os tempos atuais exigem uma cultura ampla e criativa, que permeia toda a ação na sociedade, tendo capilaridade por todas as instituições.

Ademais, Alencar e Fleith (2003) salientam que, na escola, é comum dar relevância à ignorância e à incompetência do aluno; em contrapartida, não se enfatizam suas potencialidades quanto ao talento e às habilidades individuais, criando, assim, barreiras ao desenvolvimento da criatividade. Ao se converter em sujeito da própria aprendizagem, o aluno criativo não se limita a reproduzir, mas se propõe a criar, a partir dos seus processos de aprendizagem, algo novo e valoroso para o seu processo de desenvolvimento (AMARAL; MARTINEZ, 2006). Se queremos que sejam criativos, eles precisam experimentar inúmeras novas possibilidades de mostrar sua iniciativa (MORAN, 2015). Pode-se colocar também que o professor universitário esteja mais atento ao desenvolvimento da capacidade do futuro profissional, de pensar de forma criativa e inovadora, algo indispensável para o mercado de trabalho; e isso, indubitavelmente, está a exigir novas práticas de ensino, constituindo-se no desafio aos educadores de passarem a exercer o papel de catalisadores do potencial criativo de cada aluno (ALENCAR, 1997).

Em um estudo sobre criatividade pessoal entre professores, os resultados apontam distintas barreiras que se referem direta ou indiretamente aos motivos, meios e oportunidades para a expressão da criatividade pessoal, sinalizando a necessidade de estratégias que ampliem as possibilidades de expressão criativa em professores (ALENCAR; SOUZA FLEITH, 2003). Também Alencar (1997) coloca como resultado obtido - e chama a atenção para o fato - que, de modo geral, os estudantes universitários consideram que há pouco incentivo a distintos aspectos da criatividade por parte de seus professores (ALENCAR,1997). Em 
consonância, observou-se que falta de tempo e oportunidade foram o fator mais frequentemente apontado pelos professores como barreira à expressão de sua criatividade. (ALENCAR; SOUZA FLEITH, 2003).

Nas instituições de ensino superior, Castanho (2000, p. 77) afirma que "nossas faculdades são, no geral, pouco ou nada criativas. Desenvolver a criatividade parece ser um objetivo tão simples, mas é uma das características mais raras de se encontrar na maioria de nossos jovens, educados para a atitude conformista e homogênea a que os sistemas escolares os condenam". Mas, por outro lado, encontramos nas instituições educacionais um número razoável de professores que estão experimentando essas novas metodologias, utilizando aplicativos atraentes e compartilhando o que aprendem em rede. O que predomina, no entanto, é certa acomodação, repetindo fórmulas com embalagens mais atraentes, esperando receitas, num mundo que exige criatividade e capacidade de enfrentar desafios complexos (MORAN, 2015).

\subsection{Criatividade no Ensino Presencial e na Educação a Distância}

Para Moreira (2010), os professores precisam transformar a aprendizagem numa atividade interessante e atraente, explorando as experiências individuais do estudante e as suas potencialidades criativas e imaginativas. Também a instituição de ensino precisa encontrar sua identidade educacional, em que um projeto inovador pode facilitar mudanças organizacionais e pessoais, estimulando a criatividade e propiciando transformações (MORAN, 2010). As atitudes e a atuação do docente, na aula e fora dela, são vistas como essenciais para o ensino superior cumprir a missão de preparar os alunos para a criatividade (MORAIS, ALMEIDA, 2016).

No ensino presencial, Moran (2000) coloca que, com o uso de tecnologia, as salas de aula ficam mais funcionais; os alunos utilizam notebook para pesquisa, busca de novos materiais e soluções de problemas; o professor também está mais conectado, utilizando materiais de apoio para motivar os alunos e ilustrar suas ideias. Na EAD, o desafio é tornar os cursos mais inovadores, nos quais os alunos consigam realizar a conexão da teoria à prática, e os docentes preparem aulas diversificadas para deixá-las mais atrativas (MORAN, 2015). Também vive hoje, a universidade, um paradoxo entre a necessidade de formar alunos para a criatividade e a continuidade com rotinas e valores há muito tempo enraizados (MORAIS, ALMEIDA, 2016).

Nesse sentido, Moran (2015) defende o emprego de metodologias de acordo com os objetivos traçados. A formação do aluno crítico, participativo no processo de aprendizagem e criativo, é alcançada por meio de metodologias ativas, e não inertes. Para ele, um dos modelos mais interessantes de ensinar hoje é o de concentrar no ambiente virtual o que é informação básica e deixar para a sala de aula as atividades mais criativas e supervisionadas. É o que se chama de aula invertida (MORAN, 2015). Esta metodologia pode estar plenamente integrada, com disciplinas on-line na presencial e na EAD, com materiais interessantes e comuns para ambos. Em todas as disciplinas ou módulos, os professores podem ser mais orientadores, utilizando formas criativas da sala de aula invertida (MORAN, 2015).

Na EAD, tem-se o papel do designer educacional, sendo este o responsável principal pela criação das estratégias de ensino e aprendizagem para a modalidade on-line, sendo-lhe necessária a criatividade para a execução de cada planejamento (NEVES et al., 2016). Também verificou em seu estudo que, dentre as características inerentes a esse profissional, está a criatividade, com a qual o designer educacional maneja e planeja as ações didáticas de acordo com os recursos midiáticos disponíveis (NEVES, 2016). Pode-se dizer que o professor se torna cada vez mais um gestor e orientador de caminhos coletivos e individuais, previsíveis e imprevisíveis, numa construção mais aberta, criativa e empreendedora (MORAN, 2015). 


\section{Metodologia}

A apresentação dos resultados e base teórica de pesquisa descritiva mostra características, propriedades, relações existentes na comunidade, trabalhando com dados ou fatos verificados a partir da própria realidade (CERVO, 2002). A abordagem caracteriza-se como quantitativa, pois é uma das formas pela qual podem-se testar teorias objetivas, a fim de verificar a relação existente entre as variáveis. Com isso, as variáveis podem ser medidas por meio de instrumentos, possibilitando que os dados sejam testados estatisticamente (CRESWELL, 2003).

Para coletar os dados, usamos a mensuração através do uso de escala - sendo escala um instrumento de medição que pode ser distinto ou contínuo. As escalas métricas, como classificação somada (LIKERT), tentam mensurar atitudes ou opiniões, tradicionalmente, usando de 5 a 7 pontos para avaliar a intensidade com que alguém concorda ou discorda com um conjunto de afirmações (HAIR, 2005).

Neste artigo, foi realizada uma pesquisa com base na escala desenvolvida por Alencar (1999), denominada Inventário para Identificação de Barreiras à Criatividade Pessoal, onde testamos, nesse processo, 66 variáveis, retiradas do inventário, que foram correlacionadas e agrupadas em 4 construtos principais: inibição, oportunidade, repressão e motivação, renomeadas pelas autoras, confirmando os fatores agrupados na escala de Alencar (1999). Assim, analisamos a criatividade dos egressos do ensino superior sob os aspectos dos fatores de Inibição/timidez, Falta de tempo/oportunidade, Repressão social e Falta de motivação, usando uma escala do tipo Likert de 7 pontos, variando de 1 = discordo totalmente a 7 = concordo totalmente, para alunos de todos os cursos, para verificar se existe relação ou distinção com as barreiras da criatividade dos cursos superiores EAD ou presenciais. A pesquisa foi enviada por meio das redes sociais, solicitando-se a participação de profissionais que tenham concluído o ensino superior, tanto na modalidade presencial quanto na EAD, usando-se o método da "bola de neve", passando para algumas pessoas e solicitando o compartilhamento com outras, para atingir maior número de respondentes (DEWES, 2013).

Nesse sentido, foi solicitado aos respondentes do questionário de escala Likert de 7 pontos que completassem de forma sincera a seguinte frase indutora: Eu seria mais criativo (a) se..., permitindo desenvolver a expressão criativa do indivíduo respondente.

\section{Resultados e Discussão}

Apresenta-se a análise dos resultados encontrados, onde obtivemos um total de 283 respondentes egressos do ensino superior, sendo $59,36 \%$ do sexo feminino e 40,63 do sexo masculino. Os respondentes têm entre as idades de 18 e 24 anos (0,02\%); de 25 e 35 anos (29,32\%); de 36 e 50 anos (50\%): a partir de 51 anos, 12,6\%. Do total dos respondentes, 91,51\% se encontram trabalhando; os demais estão desempregados. Ainda, do total, 85,86\% estudaram em instituições de ensino superior privadas e 14,14\% em instituições públicas. Ainda, do total dos respondentes, $84,8 \%$ estudaram na modalidade de ensino presencial e $15,2 \%$ na modalidade de EAD.

Este percentual de EAD se justifica também, porque não foi colocado período de tempo na formação dos egressos do ensino superior, e a EAD vem tendo um aumento em relação ao ensino presencial desde 2007. A modalidade a distância representava 7\% das matrículas de graduação. Nos últimos 10 anos, a educação a distância vem aumentando sua participação na educação superior. Em 2017, a EAD aumentou 17,6\% e já atende mais de 1,7 milhão de alunos, o que representa uma participação de 21,2\% dos alunos de graduação no país. A modalidade presencial apresenta o $2^{\circ}$ ano de queda no número de matrículas (INEP, 2018).

No primeiro momento, foi realizada a correlação de todos os alunos, sendo alunos das modalidades presencial ou EAD. Dessa forma, apresentam-se as correlações entre os fatores, conforme Tabela 1. 
Tabela 1: Correlações entre fatores da escala

\begin{tabular}{|c|c|c|c|c|c|}
\hline & & $\begin{array}{l}\text { Inibição/ } \\
\text { Timidez }\end{array}$ & $\begin{array}{c}\text { Falta de } \\
\text { tempo/ } \\
\text { Oportunidade }\end{array}$ & $\begin{array}{c}\text { Repressão } \\
\text { Social }\end{array}$ & $\begin{array}{l}\text { Falta de } \\
\text { motivação }\end{array}$ \\
\hline \multirow{3}{*}{$\begin{array}{l}\text { Inibição/ } \\
\text { Timidez }\end{array}$} & $\begin{array}{l}\text { Correlação } \\
\text { de Pearson }\end{array}$ & 1 & & & \\
\hline & $\begin{array}{l}\text { Sig. } \\
\text { (2 extremidades) }\end{array}$ & & & & \\
\hline & Número de alunos & 283 & & & \\
\hline \multirow{3}{*}{$\begin{array}{c}\text { Falta de } \\
\text { tempo/ } \\
\text { Oportunidade }\end{array}$} & $\begin{array}{l}\text { Correlação } \\
\text { de Pearson }\end{array}$ & ,632** & 1 & & \\
\hline & $\begin{array}{l}\text { Sig. } \\
\text { (2 extremidades) }\end{array}$ & ,000 & & & \\
\hline & Número de alunos & 283 & 283 & & \\
\hline \multirow{3}{*}{$\begin{array}{l}\text { Repressão } \\
\text { social }\end{array}$} & $\begin{array}{l}\text { Correlação } \\
\text { de Pearson }\end{array}$ &, $737 * \star$ &, $756 * *$ & 1 & \\
\hline & $\begin{array}{l}\text { Sig. } \\
\text { (2 extremidades) }\end{array}$ & ,000 & ,000 & & \\
\hline & Número de alunos & 283 & 283 & 283 & \\
\hline \multirow{3}{*}{$\begin{array}{l}\text { Falta de } \\
\text { Motivação }\end{array}$} & $\begin{array}{l}\text { Correlaçãao } \\
\text { de Pearson }\end{array}$ & ,798** &, $649 * *$ &, $637 * \star$ & 1 \\
\hline & $\begin{array}{l}\text { Sig. } \\
\text { (2 extremidades) }\end{array}$ & ,000 & ,000 & ,000 & \\
\hline & Número de alunos & 283 & 283 & 283 & 283 \\
\hline
\end{tabular}

**A correlação é significativa ao nível de 0,5\% (2 extremidades). Fonte: Dados da pesquisa.

Nesta primeira análise, verificou-se a relação significativa e positiva de todas as correlações. O coeficiente de correlação de Pearson ( $r$ ) é uma medida de associação linear entre variáveis. Para a correlação de Pearson, um valor absoluto de 1 indica uma relação linear perfeita; e quanto mais próximo de 1, maior sua relação (FIGUEIREDO FILHO; SILVA JUNIOR, 2009).

Para analisar as modalidades de ensino EAD e o Presencial, foi gerada correlação com as variáveis dos construtos para cada uma delas. Na Tabela 2, apresentam-se os resultados das correlações dos fatores da Escala de Alencar, separando-se as modalidades do Ensino EAD e do Ensino Presencial. 
Tabela 2: Correlações dos Fatores Escala de Alencar - EAD e Presencial

\begin{tabular}{|c|c|c|c|c|c|}
\hline \multicolumn{2}{|r|}{ EAD } & \multirow{2}{*}{$\begin{array}{c}\text { Inibição/ } \\
\text { Timidez }\end{array}$} & \multirow[t]{2}{*}{$\begin{array}{c}\text { Falta de } \\
\text { tempo/ } \\
\text { Oportunidade }\end{array}$} & \multirow[t]{2}{*}{$\begin{array}{l}\text { Repressão } \\
\text { social }\end{array}$} & \multirow[t]{2}{*}{$\begin{array}{l}\text { Falta de } \\
\text { Motivação }\end{array}$} \\
\hline \multirow{3}{*}{$\begin{array}{l}\text { Inibição/ } \\
\text { Timidez }\end{array}$} & $\begin{array}{l}\text { Correlação } \\
\text { de Pearson }\end{array}$ & & & & \\
\hline & $\begin{array}{l}\text { Sig. } \\
\text { ( } 2 \text { extremidades) }\end{array}$ & & & & \\
\hline & Número de alunos & 43 & & & \\
\hline \multirow{3}{*}{$\begin{array}{c}\text { Falta de } \\
\text { tempo/ } \\
\text { Oportunidade }\end{array}$} & $\begin{array}{l}\text { Correlação de } \\
\text { Pearson }\end{array}$ &, $769 * *$ & 1 & & \\
\hline & $\begin{array}{l}\text { Sig. } \\
\text { ( } 2 \text { extremidades) }\end{array}$ & ,000 & & & \\
\hline & Número de alunos & 43 & 43 & & \\
\hline \multirow{3}{*}{$\begin{array}{l}\text { Repressão } \\
\text { social }\end{array}$} & $\begin{array}{l}\text { Correlação de } \\
\text { Pearson }\end{array}$ &, $834^{\star \star}$ &, $772 * \star$ & 1 & \\
\hline & $\begin{array}{l}\text { Sig. } \\
\text { ( } 2 \text { extremidades) }\end{array}$ & ,000 &, 000 & & \\
\hline & Número de alunos & 43 & 43 & 43 & \\
\hline \multirow{3}{*}{$\begin{array}{c}\text { Falta de } \\
\text { Motivação }\end{array}$} & $\begin{array}{l}\text { Correlação de } \\
\text { Pearson }\end{array}$ &, $849 * \star$ &, $748 * \star$ &, $720 * \star$ & 1 \\
\hline & $\begin{array}{l}\text { Sig. } \\
\text { ( } 2 \text { extremidades) }\end{array}$ & ,000 &, 000 &, 000 & \\
\hline & Número de alunos & 43 & 43 & 43 & 43 \\
\hline \multicolumn{2}{|c|}{ PRESENCIAL } & $\begin{array}{l}\text { Inibição/ } \\
\text { Timidez }\end{array}$ & $\begin{array}{c}\text { Falta de } \\
\text { tempo/ } \\
\text { Oportunidade }\end{array}$ & $\begin{array}{l}\text { Repressão } \\
\text { social }\end{array}$ & $\begin{array}{l}\text { Falta de } \\
\text { Motivação }\end{array}$ \\
\hline \multirow{3}{*}{$\begin{array}{c}\text { Inibição/ } \\
\text { Timidez }\end{array}$} & $\begin{array}{l}\text { Correlação de } \\
\text { Pearson }\end{array}$ & 1 & & & \\
\hline & $\begin{array}{l}\text { Sig. } \\
\text { ( } 2 \text { extremidades) }\end{array}$ & & & & \\
\hline & Número de alunos & 240 & & & \\
\hline \multirow{3}{*}{$\begin{array}{c}\text { Falta de } \\
\text { tempo/ } \\
\text { Oportunidade }\end{array}$} & $\begin{array}{l}\text { Correlação } \\
\text { de Pearson }\end{array}$ &, $606 * *$ & 1 & & \\
\hline & $\begin{array}{l}\text { Sig. } \\
\text { ( } 2 \text { extremidades) }\end{array}$ & ,000 & & & \\
\hline & Número de alunos & 240 & 240 & & \\
\hline \multirow{3}{*}{$\begin{array}{l}\text { Repressão } \\
\text { social }\end{array}$} & $\begin{array}{l}\text { Correlação } \\
\text { de Pearson }\end{array}$ &, $718^{* *}$ &, $754^{\star *}$ & 1 & \\
\hline & $\begin{array}{l}\text { Sig. } \\
\text { ( } 2 \text { extremidades) }\end{array}$ & ,000 &, 000 & & \\
\hline & Número de alunos & 240 & 240 & 240 & \\
\hline
\end{tabular}




\begin{tabular}{|c|c|c|c|c|c|}
\hline \multirow{3}{*}{$\begin{array}{l}\text { Falta de } \\
\text { Motivação }\end{array}$} & $\begin{array}{l}\text { Correlação de } \\
\text { Pearson }\end{array}$ & ,788** &, 624 ** & ,620** & 1 \\
\hline & $\begin{array}{l}\text { Sig. } \\
\text { (2 extremidades) }\end{array}$ & ,000 & ,000 & ,000 & \\
\hline & Número de alunos & 240 & 240 & 240 & 240 \\
\hline
\end{tabular}

**A correlação é significativa no nível 0,01 (2 extremidades).
*A correlação é significativa no nível 0,05 (2 extremidades).

Dessa forma, verificou-se que na correlação de Pearson houve associação positiva entre os fatores inibição, oportunidade, repressão e motivação no Ensino EAD e Ensino Presencial.

Esse resultado vem a seguir os resultados de estudos anteriores, em que Alencar e Fleith (2004) mostram a importância dessas variáveis sob a influência e o desenvolvimento do potencial criativo em sala de aula, onde há insuficiência de profissionais criativos que dominem estratégias para desenvolver a criatividade num indivíduo no ambiente educacional. Docentes e estudantes possuem ideias errôneas sobre criatividade; desta forma, a discussão ampla sobre criatividade na educação se faz necessária (CRAFT, 2007). Portanto, indiferentemente do ensino EAD ou presencial, é de extrema importância a reflexão constante dos docentes quanto às suas práticas pedagógicas e ao investimento em uma formação voltada para a criatividade, para construção de jovens profissionais críticos e criativos.

Na Tabela 3, apresentam-se os resultados das correlações dos fatores da Escala de Alencar referentes ao Ensino EAD e ao Ensino Presencial correlacionados com análise das variáveis de controle, sendo: idade e renda.

Tabela 3: Correlações dos Fatores Escala de Alencar e Variáveis de Controle

\begin{tabular}{|c|c|c|c|c|c|c|c|}
\hline \multicolumn{2}{|r|}{ EAD } & $\begin{array}{l}\text { Inibição/ } \\
\text { Timidez }\end{array}$ & $\begin{array}{l}\text { Falta de tempo/ } \\
\text { Oportunidade }\end{array}$ & $\begin{array}{c}\text { Repressão } \\
\text { social }\end{array}$ & $\begin{array}{c}\text { Falta de } \\
\text { Motivação }\end{array}$ & Idade & Renda \\
\hline \multirow{3}{*}{$\begin{array}{c}\text { Inibição/ } \\
\text { Timidez }\end{array}$} & $\begin{array}{l}\text { Correlação } \\
\text { de Pearson }\end{array}$ & 1 & & & & & \\
\hline & $\begin{array}{l}\text { Sig. } \\
\text { (2 extremidades) }\end{array}$ & & & & & & \\
\hline & $\begin{array}{l}\text { Número } \\
\text { de alunos }\end{array}$ & 43 & & & & & \\
\hline \multirow{3}{*}{$\begin{array}{l}\text { Falta de } \\
\text { tempo/ } \\
\text { Oportuni- } \\
\text { dade }\end{array}$} & $\begin{array}{l}\text { Correlação de } \\
\text { Pearson }\end{array}$ & ,769** & 1 & & & & \\
\hline & $\begin{array}{l}\text { Sig. } \\
\text { ( } 2 \text { extremidades) }\end{array}$ & ,000 & & & & & \\
\hline & $\begin{array}{l}\text { Número } \\
\text { de alunos }\end{array}$ & 43 & 43 & & & & \\
\hline \multirow{3}{*}{$\begin{array}{l}\text { Repressão } \\
\text { social }\end{array}$} & $\begin{array}{l}\text { Correlação } \\
\text { de Pearson }\end{array}$ &, $834^{* *}$ &, $772^{* \star}$ & 1 & & & \\
\hline & $\begin{array}{l}\text { Sig. } \\
\text { ( } 2 \text { extremidades) }\end{array}$ & ,000 & ,000 & & & & \\
\hline & $\begin{array}{l}\text { Número } \\
\text { de alunos }\end{array}$ & 43 & 43 & 43 & & & \\
\hline
\end{tabular}




\begin{tabular}{|c|c|c|c|c|c|c|c|}
\hline \multirow{3}{*}{$\begin{array}{l}\text { Falta de } \\
\text { Motivação }\end{array}$} & $\begin{array}{l}\text { Correlação } \\
\text { de Pearson }\end{array}$ &, $849 * *$ &, $748 * *$ &, 720 ** & 1 & & \\
\hline & $\begin{array}{l}\text { Sig. } \\
\text { ( } 2 \text { extremidades) }\end{array}$ & ,000 &, 000 & ,000 & & & \\
\hline & $\begin{array}{l}\text { Número } \\
\text { de alunos }\end{array}$ & 43 & 43 & 43 & 43 & & \\
\hline \multirow{3}{*}{ Idade } & $\begin{array}{l}\text { Correlação } \\
\text { de Pearson }\end{array}$ & $-0,206$ & 0,055 & $-0,097$ & $-0,152$ & 1 & \\
\hline & $\begin{array}{l}\text { Sig. } \\
\text { ( } 2 \text { extremidades) }\end{array}$ & 0,186 & 0,724 & 0,537 & 0,331 & & \\
\hline & $\begin{array}{l}\text { Número } \\
\text { de alunos }\end{array}$ & 43 & 43 & 43 & 43 & 43 & \\
\hline \multirow{3}{*}{ Renda } & $\begin{array}{l}\text { Correlação } \\
\text { de Pearson }\end{array}$ & 0,024 & $-0,135$ & $-0,047$ & $-0,049$ & 0,048 & 1 \\
\hline & $\begin{array}{l}\text { Sig. } \\
\text { ( } 2 \text { extremidades) }\end{array}$ & 0,876 & 0,387 & 0,765 & 0,756 & 0,76 & \\
\hline & $\mathrm{N}$ & 43 & 43 & 43 & 43 & 43 & 43 \\
\hline \multicolumn{2}{|c|}{ PRESENCIAL } & $\begin{array}{l}\text { Inibição/ } \\
\text { Timidez }\end{array}$ & $\begin{array}{l}\text { Falta de tempo/ } \\
\text { Oportunidade }\end{array}$ & $\begin{array}{l}\text { Repressão } \\
\text { social }\end{array}$ & $\begin{array}{l}\text { Falta de } \\
\text { Motivação }\end{array}$ & Idade & Renda \\
\hline \multirow{3}{*}{$\begin{array}{l}\text { Inibição/ } \\
\text { Timidez }\end{array}$} & $\begin{array}{l}\text { Correlação } \\
\text { de Pearson }\end{array}$ & 1 & & & & & \\
\hline & $\begin{array}{l}\text { Sig. } \\
\text { ( } 2 \text { extremidades) }\end{array}$ & ,000 & & & & & \\
\hline & $\begin{array}{l}\text { Número } \\
\text { de alunos }\end{array}$ & 240 & & & & & \\
\hline \multirow{3}{*}{$\begin{array}{l}\text { Falta de } \\
\text { tempo/ } \\
\text { Oportuni- } \\
\text { dade }\end{array}$} & $\begin{array}{l}\text { Correlação } \\
\text { de Pearson }\end{array}$ &, $606 * *$ & 1 & & & & \\
\hline & $\begin{array}{l}\text { Sig. } \\
\text { ( } 2 \text { extremidades) }\end{array}$ & ,000 & ,000 & & & & \\
\hline & $\begin{array}{l}\text { Número de } \\
\text { alunos }\end{array}$ & 240 & 240 & & & & \\
\hline \multirow{3}{*}{$\begin{array}{l}\text { Repressão } \\
\text { social }\end{array}$} & $\begin{array}{l}\text { Correlação de } \\
\text { Pearson }\end{array}$ &, $718 * \star$ &, $754 * \star$ & 1 & & & \\
\hline & $\begin{array}{l}\text { Sig. ( } 2 \text { extremi- } \\
\text { dades) }\end{array}$ & ,000 & ,000 & & & & \\
\hline & $\begin{array}{l}\text { Número de } \\
\text { alunos }\end{array}$ & 240 & 240 & 240 & & & \\
\hline \multirow{3}{*}{$\begin{array}{l}\text { Falta de } \\
\text { Motivação }\end{array}$} & $\begin{array}{l}\text { Correlação de } \\
\text { Pearson }\end{array}$ &, $788 * \star$ &, $624^{\star \star}$ &, $620 * \star$ & 1 & & \\
\hline & $\begin{array}{l}\text { Sig. } \\
\text { ( } 2 \text { extremidades) }\end{array}$ & ,000 & ,000 & ,000 & & & \\
\hline & $\begin{array}{l}\text { Número } \\
\text { de alunos }\end{array}$ & 240 & 240 & 240 & 240 & & \\
\hline \multirow{3}{*}{ Idade } & $\begin{array}{l}\text { Correlação } \\
\text { de Pearson }\end{array}$ &,$- 145 *$ & $-0,064$ & $-0,097$ &,$- 157 *$ & 1 & \\
\hline & $\begin{array}{l}\text { Sig. } \\
\text { (2 extremidades) }\end{array}$ & 0,025 & 0,327 & 0,133 & 0,015 & & \\
\hline & $\begin{array}{l}\text { Número } \\
\text { de alunos }\end{array}$ & 240 & 240 & 240 & 240 & 240 & \\
\hline
\end{tabular}




\begin{tabular}{l|l|c|c|c|c|c|c}
\hline \multirow{2}{*}{ Renda } & $\begin{array}{l}\text { Correlação } \\
\text { de Pearson }\end{array}$ &,$- 214^{* *}$ & $-0,039$ & $-0,12$ & $-0,121$ &, $323^{* *}$ & 1 \\
\cline { 2 - 8 } & $\begin{array}{l}\text { Sig. } \\
\text { (2 extremidades) }\end{array}$ & 0,001 & 0,551 & 0,063 & 0,062 &, 000 & \\
\cline { 2 - 8 } & $\begin{array}{l}\text { Número } \\
\text { de alunos }\end{array}$ & 240 & 240 & 240 & 240 & 240 & 240 \\
\hline
\end{tabular}

\footnotetext{
**A correlação é significativa no nível 0,01 (2 extremidades).

*A correlação é significativa no nível 0,05 (2 extremidades).
}

Analisando-se os fatores para o ensino EAD, observou-se que idade e renda não são significativas para a criatividade. Isso quer dizer que se pode esperar que a renda tenha uma evolução constante ao longo do ciclo de vida de um trabalhador, seguida de experiência/idade, aumento de produtividade, entre outros fatores. Contudo, a renda do trabalho pode ser mais elevada para aqueles que possuem maior escolaridade, sendo que todas essas variáveis influenciam no rendimento do trabalhador. (COSTANZI, 2015).

Já correlacionando as variáveis de controle para o ensino Presencial, observou-se que a idade se correlaciona negativamente com a motivação. Conforme Sternberg e Lubart (1999, p. 339), "ao examinar um produto, processo ou pessoa criativa, não é possível ignorar a influência do ambiente". Essa citação vem a seguir aos resultados de estudos anteriores de Land e Jarman (1990), nos quais realizaram um estudo longitudinal no qual crianças foram testadas e acompanhadas até seus quinze anos de idade, resultando num índice decrescente de criatividade em relação à idade dos sujeitos, comprovando que a influência do ambiente impacta diretamente na criatividade do indivíduo. Também, ao fator idade, pode-se analisar que idade se correlacionada negativamente com inibição, ou seja, quanto maior a idade do indivíduo, menor a inibição - fato que nos traz à tona o antigo chinês, exemplo do autor do livro Tao Te King, O Velho Sábio, Lao Tzé: Onde a velhice representa o acúmulo de experiência e aprendizado de vida (PAULA, 2016). Conforme Schopenhauer (2006, p. 01), sabedoria é saber levar a vida de forma agradável e mais feliz possível. Ainda no contexto do fator inibição, observa-se que o fator renda se correlaciona negativamente com a inibição; dessa forma, quando maior a renda, menor a inibição do indivíduo.

Comparando as correlações do Ensino EAD e Ensino Presencial, embora os resultados entre os estudos seja tarefa difícil, posto que os mesmos se baseiam em diferentes perfis de egressos, frequentemente subjetivos, assim pode-se dizer que embora ambos os ensinos se correlacionem de forma positiva quanto às barreiras da criatividade (inibição/timidez, oportunidade, repressão social, falta de motivação), o Ensino EAD ainda mostra resultados superiores aos do Ensino Presencial. O propósito do Ensino EAD é crucial para o desenvolvimento social do Brasil, porém o desafio ainda está na mudança de mentalidade em prol de uma EAD efetiva. (COSTANZI, et al., 2015).

\section{Conclusão}

Diante dos resultados apresentados, verificou-se que as barreiras da criatividade apresentam significância positiva para ambas as modalidades, sendo um fator predominante para a quebra de um paradoxo presente nas organizações, devido à constante procura de mão de obra qualificada, que traga ideias criativas e inovem o âmbito profissional.

Em concordância que a universidade também precisa se preocupar em criar um ambiente propício à criatividade e à inovação, sob o risco de formar profissionais com técnicas apuradas, mas com dificuldades em atender às exigências da nova sociedade (BARBIERI, 2000), concluindo-se que os ensinos se correlacionem quanto às barreiras da criatividade demonstrando ainda desta forma que o ensino EAD 
apresenta resultados superiores aos do Ensino Presencial, mostrando que está sendo uma modalidade em ascensão, e se destacando como modalidade de ensino.

Desta forma, é notável que os processos realizados em grupo em instituições EAD estão diretamente ligados à confiança e à socialização entre os indivíduos (TAGGAR, 2002). Esses fatores afetam diretamente a criatividade, bem como a comunicação, o engajamento e a administração de conflitos. Essas equipes, com processos bem desenvolvidos, envolvem a colaboração dos indivíduos do grupo, elaborando síntese de ideias, dentre outros fatores que possuem melhores resultados. Todavia, conforme Taggar, 2002, quando os grupos baixam a incidência nos processos, a criatividade pode ser neutralizada.

Este artigo aborda que o ensino presencial e o EAD possuem diferenças em alguns aspectos; porém, neste mesmo âmbito, podemos desenvolver bons profissionais para o mercado de trabalho, incrementando todas as capacidades humanas do indivíduo em sua transição de ensino.

As pesquisas encontradas sobre criatividade, normalmente, referem-se ao ensino presencial; porém envolver o ensino EAD e a criatividade é um tema de extrema relevância no atual cenário educacional, devido à ascendente importância, para o bom desempenho profissional. Para trabalhos futuros, sugerimos avaliar (a) outras barreias de criatividade, podendo comparar-se ainda às modalidades de EAD e presencial, nas formas de uso da criatividade sentidas por estudantes, egressos ou profissionais; (b) analisar um estudo profundo entre a idade e a renda nas duas modalidades de ensino.

A competência criatividade está no topo das competências do futuro, sendo citada como diferencial do profissional no mercado de trabalho nos próximos anos. Por isso, realmente merece a devida atenção para sua pesquisa e desenvolvimento por parte dos educandos e profissionais altamente qualificados no mercado de trabalho.

\section{Referências}

ALENCAR, E.M.L.S. de; FLEITH, D. S. Criatividade. Brasília. DF: Ed. Unb, 1993.

ALENCAR, E.M.L.S. de. O estímulo à criatividade no contexto universitário. Psicologia escolar e educacional, v. 1, n. 2-3, p. 29-37, 1997.

ALENCAR, E.M.L.S. de. Barreiras à criatividade pessoal: desenvolvimento de um instrumento de medida. Psicologia Escolar e Educacional, v. 3, n. 2, p. 123-132, 1999.

ALENCAR, E.M.L.S. de; MARTINEZ, A. M. Barreiras à expressão da criatividade entre profissionais brasileiros, cubanos e portugueses. Psicologia escolar e Educacional, v. 2, n. 1, p. 23-32, 1998.

ALENCAR, E.M.L.S. de; DE SOUZA FLEITH, D. Criatividade pessoal: fatores facilitadores e inibidores segundo estudantes de engenharia. Magis: Revista Internacional de Investigación en Educación, v. 1, n. 1, p. 113-126, 2008.

ALENCAR, E.M.L.S. de.; DE SOUZA FLEITH, D. Criatividade. Múltiplas perspectivas. Brasília (DF): Ed. UnB, 2009.

AMABILE, T. M. Creativity in context: Update to. 1996.

AMABILE, T. M.; MUELLER, J. Assessing creativity and its antecedents: An exploration of the componential theory of creativity. 2008.

AMARAL, A. L. N.; MITJÁNS MARTINEZ, A. Aprendizagem e criatividade no contexto universitário. Psicología para América Latina, n. 8, p. 0-0, 2006. 
BARBIERI, F. F. C. M. A criatividade nas universidades: construção de um modelo para avaliar o perfil criativo das instituições de ensino superior. 2018.

BARRON, F. Creativity and psychological health. 1963.

BRASIL. INSTITUTO NACIONAL DE ESTUDOS E PEQUISAS EDUCACIONAIS ANÍSIO TEIXEIRA. Sinopse estatística da Educação Superior 2017. Brasília: Inep, 2018. Disponível em http://portal.inep.gov.br/basica-censo-escolar-sinopese-sinopse. Acesso em: 15 ago. 2019.

CARDOSO, J.; MOREIRA, B.; BATTISTI, P.. Gestão de pessoas em Polos de Apoio Presencial: Contextos e desafios. In: Anais do VIII Congresso, 2011.

CASTANHO, M. E. L. M. A criatividade na sala de aula universitária. Pedagogia universitária. A aula em foco, p. 75-89, 2000.

CERVO, A. L; BERVIAN, P. A. Metodologia científica. 5. ed. São Paulo: Prentice Hall, 2002.

COSTANZI, R. N.; ANSILIERO, G. Reflexões iniciais sobre a reforma da previdência: a polêmica questão de gênero na determinação da idade mínima para aposentadoria. Informações fipe, v. 436, n. 1, p. 16 $24,2017$.

CRAFT, A. Creativity in schools. Developing creativity in higher education (pp. 19-28). London: Routledge, 2007.

CRESWELL, J. W. Projeto de Pesquisa: métodos qualitativo, quantitativo e misto (LO Rocha, Trad.) Porto Alegre: Artmed, 2003.

CROPLEY, A. In praise of convergent thinking. Creativity research journal, v. 18, n. 3, p. 391-404, 2006.

CROPLEY, D; CROPLEY, A. A psychological taxonomy of organizational innovation: Resolving the paradoxes. Creativity Research Journal, v. 24, n. 1, p. 29-40, 2012.

DAVIS, R. D.; BRAUN, E. M. O dom da dislexia. Rio de Janeiro: Rocco, 2004.

DE ALENCAR, E. M. L. S.; DE SOUZA FLEITH, D. Barreiras à criatividade pessoal entre professores de distintos níveis de ensino. Psicologia: Reflexão e Crítica, v. 16, n. 1, p. 63-69, 2003.

DE ALENCAR, E. M. L. S.; DE SOUZA FLEITH, D. Inventario de Práticas Docentes que Favorecem a Criatividade no Ensino Superior. Psicologia: reflexão e crítica, v. 17, n. 1, p. 105-110, 2004.

DEWES, J. O. Amostragem em Bola de Neve e Respondent-Driven Sampling: uma descrição dos métodos. 2013.

FIGUEIREDO FILHO, D. B.; SILVA JÚNIOR, J. A. D. Desvendando os Mistérios do Coeficiente de Correlação de Pearson (r). 2009.

FORD, C. M. A theory of individual creative action in multiple social domains. Academy of Management review, v. 21, n. 4, p. 1112-1142, 1996.

GARDNER, H. Mentes que mudam: a arte e a ciência de mudar as nossas ideias e as dos outros. Penso Editora, 2016.

HAIR, Jr. et al. Fundamentos de métodos de pesquisa em administração. Porto Alegre: Bookman, $2005 a$.

KAUFMAN, J. C.; BAER, J. Sure, i'm creative-but not in mathematics!: Self-reported creativity in diverse domains. Empirical studies of the Arts, v. 22, n. 2, p. 143-155, 2004.

KUBIE, Lawrence Schlesinger. Neurotic distortion of the creative process. 1958. 
LAND G.; JARMANN, B. Ponto de Ruptura e Transformação. São Paulo: Cultrix. 1990.

MORAN, J. M. Ensino e aprendizagem inovadores com tecnologias. Informática na educação: teoria \& prática, v. 3, n. 1, 2000.

MORÁN, J. M. Mudando a educação com metodologias ativas. Coleção Mídias Contemporâneas. Convergências Midiáticas, Educação e Cidadania: aproximações jovens, v. 2, n. 1, p. 15-33, 2015.

MORAIS, M. F.; ALMEIDA, L. S. Percepções sobre criatividade: Estudo com estudantes do Ensino Superior. Revista Portuguesa de Educação, v. 29, n. 2, p. 141-162, 2016.

MOREIRA, J. A.; MONTEIRO, A. O trabalho pedagógico em cenários presenciais e virtuais no ensino superior. Educação, Formação \& Tecnologias - ISSN 1646-933X, v. 3, n. 2, p. 82-94, 2010.

MOTTA FILHO, C. Ensaio sobre a timidez. Martins, 1969.

NEVES, M. et al. Design Educacional em Educação a Distância: Conceitos, Função e Criatividade. SIED: EnPED-Simpósio Internacional de Educação a Distância e Encontro de Pesquisadores em Educação a Distância, 2016.

O'REILLY R. D.; Charles A.; TUSHMAN, M. L. The ambidextrous organization. Harvard business review, v. 82, n. 4, p. 74, 2004.

PARK, N. K.; CHUN, M. Y.; LEE, J. Revisiting individual creativity assessment: Triangulation in subjective and objective assessment methods. Creativity Research Journal, v. 28, n. 1, p. 1-10, 2016.

PAULA, M. F. Os idosos do nosso tempo e a impossibilidade da sabedoria no capitalismo atual. Serviço Social \& Sociedade, n. 126, p. 262-280, 2016.

PERRY-SMITH, J. E.; SHALLEY, C. E. The social side of creativity: A static and dynamic social network perspective. Academy of management review, v. 28, n. 1, p. 89-106, 2003.

PRIGOGINE, I. Criatividade da natureza, criatividade humana. Ponto-e-Vírgula: Revista de Ciências Sociais, n. 6, 2009.

RICKARDS, T.; JONES, L. J. Towards the identification of situational barriers to creative behaviors: The development of a self $\square$ report inventory. Creativity Research Journal, v. 4, n. 4, p. 303-315, 1991.

ROBINSON, A. Exceptional Creativity in Science and Technology: Individuals, Institutions, and Innovations. Ed. Templeton Foundation Press, 2013.

RUNCO, M. Personal creativity and culture. In: Creativity: When east meets west. 2004. p. 9-21.

SCHOPENHAUER, A. Aforismo para a sabedoria de vida. São Paulo: Martins Fontes, 2006.

SHALLEY, C. E.; ZHOU, J; OLDHAM, G. R. The effects of personal and contextual characteristics on creativity: Where should we go from here? Journal of management, v. 30, n. 6, p. 933-958, 2004.

STEIN, K. B.; CHU, C. Dimensionality of Barron's Ego-Strength Scale. Journal of Consulting Psychology, v. 31, n. 2 , p. $153,1967$.

STERNBERG, R. J.; LUBART, T. I. The concept of creativity: Prospects and paradigms. Handbook of creativity, v. 1, p. 3-15, 1999.

TAGGAR, S. Individual creativity and group ability to utilize individual creative resources: a multilevel model. Academy of Management Journal, v. 45, n. 2, pp. 315-330, 2002. 
TALBOT, R. J. Creativity in the organizational context: Implications for training. Nurturing and developing creativity: The emergence of a discipline, p. 177-214, 1993.

TORRANCE, E. Paul. The nature of creativity as manifest in its testing. The nature of creativity, p. 43-75, 1988.

VERGARA, S. C.; CARPILOVSKY, M. P. A metáfora da organização como sistema criativo. Revista de Administração Pública, v. 32, n. 3, p. 77-98, 1998.

WECHSLER, S. M. CRIATIVIDADE. Descobrindo e Encorajando. Ed. Psy, SP, 1998. 